\title{
ANALYSIS OF STAGNATION POINT FLOW OVER A STRETCHING/SHRINKING SURFACE
}

\author{
M'bagne F. M'bengue and Joseph E. Paullet*
}

\begin{abstract}
In this article we analyze the boundary value problem governing stagnation-point flow of a fluid with a power law outer flow over a surface moving with a speed proportional to the outer flow. The flow is characterized by two physical parameters; $\varepsilon$, which measures the stretching ( $\varepsilon>0)$ or shrinking $(\varepsilon<0)$ of the sheet relative to the outer flow, and $n>0$, the power law exponent. In the case of aiding flow $(\varepsilon>0)$, where the (stretching) surface and the outer flow move in the same direction, we prove existence of a solution for all values of $n$. For opposing flow $(\varepsilon<0)$, where the (shrinking) surface and the outer flow move in opposite directions, the situation is much more complicated. For $-1<\varepsilon<0$ and all $n$ we prove a solution exists. However, for $\varepsilon \leqslant-1$, we prove there exists a value, $\varepsilon_{\text {crit }}(n) \leqslant-1$, such that no solutions exist for $\varepsilon \leqslant \varepsilon_{\text {crit }}$. For $n=1 / 7$ and $n=1 / 3$ we prove that $\varepsilon_{\text {crit }}=-1$. For other values of $n$, we derive bounds which illustrate the complicated nature of the existence/nonexistence boundary for opposing $(\varepsilon<0)$ flows.
\end{abstract}

Mathematics subject classification (2020): 34B15, 76D10.

Keywords and phrases: Stagnation point flow, opposing flow, nonlinear boundary value problem, existence, nonexistence.

\section{REFERENCES}

[1] L. J. CRAne, Flow past a stretching plate, Z. Ange. Math. Phys., 21 (1970), pp. 645-647.

[2] A. C. ERINGEn, Theory of thermomicrofluids, J. Math. Anal. Appl., 38 (1972), pp. 480-496.

[3] B. ERmentrout, XPPAUT, http://www.math.pitt.edu/\$\sim\$bard/xpp/xpp.html.

[4] A. ISHAK, Y. Y. LOK AND I. POP, Stagnation-point flow over a shrinking sheet in a micropolar fluid, Int. J. Eng. Sci., 197 (2010), pp. 1417-1427.

[5] A. ISHAK, R. NAZAR AND I. POP, Stagnation flow of a micropolar fluid towards a vertical permeable surface, Int. Comm. Heat Mass Trans., 35 (2008), pp. 276-281.

[6] M. KHADER AND R. SHARMA, Evaluating the unsteady MHD micropolar fluid flow past a stretching/shrinking sheet with heat source and thermal radiation: implementing fourth order predictorcorrector FDM, Math. and Comp. in Sim., 181 (2021), 333-350.

[7] J. H. MER KIN, Multiple similarity solutions in boundary-layer flow on a moving surface, Acta Mech., 229 (2018), pp. 4279-4294.

[8] M. MiklaVČIC̆ AND C. Y. WANG, Viscous flow due to a shrinking sheet, Q. Appl. Math., 64 (2006), pp. 283-290.

[9] R. NAZAR, N. Amin, D. FiliP AND I. Pop, Stagnation point flow of a micropolar fluid towards a stretching sheet, Int. J. Nonlinear Mech., 39 (2004), pp. 1227-1235.

[10] C. Y. WANG, The three-dimensional flow due to a stretching plate, Phys. Fluids, 27 (1984), pp. 19151917.

[11] C. Y. WANG, Stagnation-point flow towards a shrinking sheet, Int. J. Nonlinear Mech., 43 (2008), pp. 377-382.

[12] Z. ZiabAKhSh, G. Domairry AND H. BARARnia, Analytical solutions of non-Newtonian micropolar fluid flow with uniform suction/blowing and heat generation, J. Taiwan Inst. Chem. Eng., 40 (2009), pp. 443-451. 
[13] K. ZAIMI AND A. ISHAK, Stagnation-point flow and heat transfer over a nonlinearly stretching/shrinking sheet in a micropolar fluid, Abs. Appl. Anal., (2014), Article ID: 261630. 